\title{
Assessing the adequacy of hemodialysis as renal replacement therapy
}

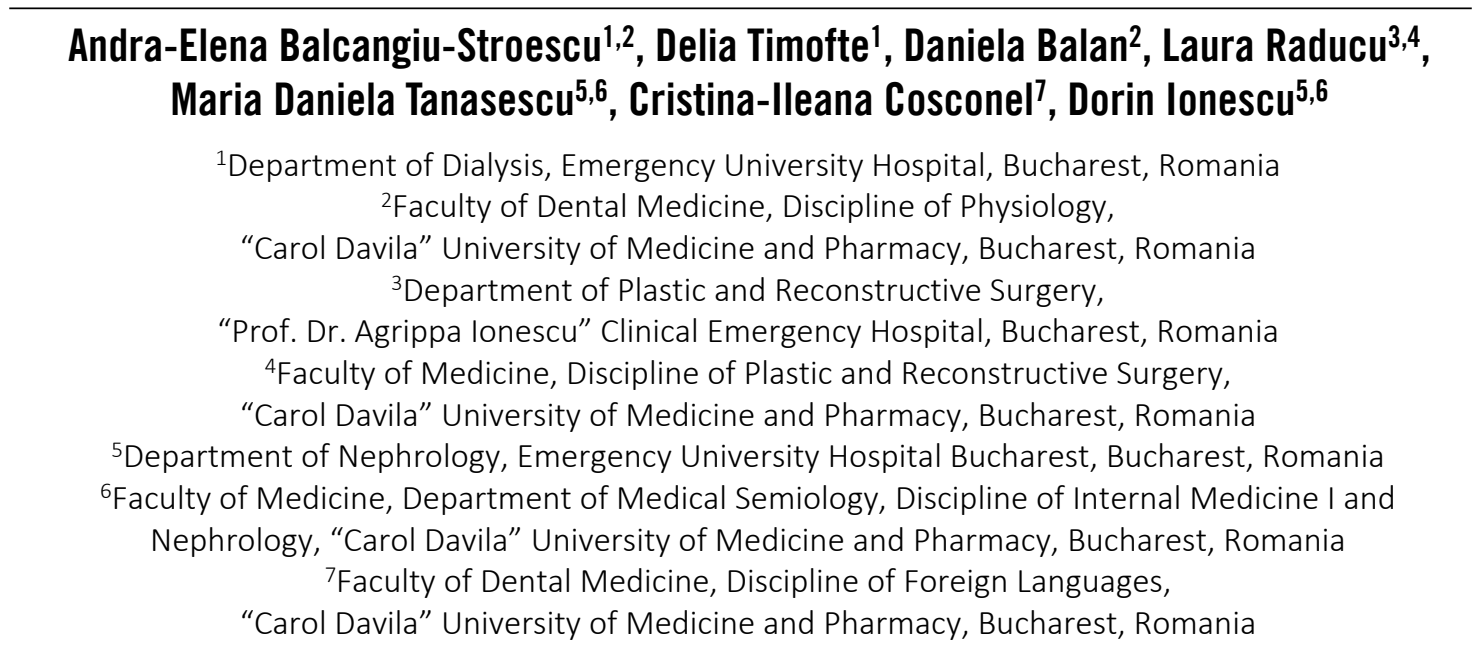

\begin{abstract}
Following the increase in incidence and prevalence of the risk factors responsible for the occurence of renal impairment is the increase of patients suffering from chronic kidney disease (CKD).

As the renal function declines and the end stage of the chronic kidney disease is reached, it is necessary to start one of the following methods for substituting the renal function: renal transplantation, hemodialysis or peritoneal dialysis. The treatment of choice for most patients is hemodialysis, both in Romania and abroad in the international medical centers. According to official data, the number of patients undergoing hemodialysis is constantly growing.

Hemodialysis adequacy evaluation instruments must be familiar among clinicians in order to provide a treatment that meets the quality standards.
\end{abstract}

Keywords: chronic kidney disease, hemodialysis adequacy, morbidity rate, mortality rate

\section{INTRODUCTION}

The chronic kidney disease (CKD) is a public health problem in Romania, since it affects over $11 \%$ of the patients, which means the disease must be diagnosed as early as possible. The patients at risk for CKD are identified by the family physicians, but only $2 \%$ of the cases are diagnosed. In this way, the efficient therapeutical measures are not used enough, and the referral to the nephrologist is delayed, as is the onset of the renal substituting therapy, which increases the mortality/morbidity rates and the health care expenses (1).
High blood pressure, diabetes, glomerulonephritis, different kinds of urinary obstructions or systemic diseases, such as: lupus erythematosus, rheumatoid polyarthritis, scleroderma are conditions which favor the occurrence of chronic kidney disease $(2,3)$. The association between chronic kidney disease and the increase of death risk emphasize the importance of these patients' correct management (4). The death risk in this group of patients is increased by the varied associated conditions, especially cardiovascular involvement. Patients undergoing renal replacement therapy have a high- 
er rate of cardiovascular pathologies compared to the general population (5). Inflammation is an important risk factor in the survival of patients undergoing chronic dialysis; thus, the increased level of inflammation is a significant trigger for the rise of the death risk (6). To be more specific, the specialty literature describes more and more frequently, the association between oxidative stress and microvascular complications, diabetic renal disease included, in diabetic patients (7). Diabetic nephropathy decreases the patients' life expectancy and increases the mortality risk, so it represents a negative prognosis (8). A correct management, including both pharmacological treatment and diet, is of utmost importance in these patients (9).

Once the renal function declines and the chronic kidney disease reaches the end stage, it is necessary to start one of the substituting methods for the renal functions: hemodialysis, peritoneal dialysis or renal transplantation. Hemodialysis is the treatment of choice for most patients, both in Romania and in international medical settings. The number of patients undergoing hemodialysis is constantly growing, according to official data. Over 300,000 patients are treated with hemodialysis worldwide, which ensures both their survival and the quality of life maintenance (1).

The dialysis machines have improved from a technical point of view, and so has their performance over the past years. The large number of studies done have also allowed for a better understanding of the physiopathology of uremia, the efficient control of anemia and other co-morbidities and has increased the patients' compliance to dialysis. Nevertheless, in spite of all the evidence, mortality and morbidity of dialysed patients are significantly higher than those in the general population (10).

The adequate care of patients on dialysis includes collecting, processing and analyzing the data regarding the main treatment and the treatment of comorbidities. The analysis of these data allows for the identification of the opportunities to improve patient's care, a more personal treatment, which can be monitored and adjusted and a reduction costs $(10,11)$.

A number of instruments used to assess the efficiency of hemodialysis has been described in the specialist literature. These include: periodic clinical monitoring, the nutrition status assessment, the assessment of the patient's psychological status, social integration and quality of life, mainly expressed by his/her "state of well-being". Certain quantitative, objective parametres are also used in practice; they are: the evaluation of clearance of small- molecular- weight solutes (e.g.urea) and of ultrafiltration, monitoring blood pressure, the protein catabolic rate, anemia, acidosis and of minedral and bone disorders. All these are common complications, which disturb homeostasis and negatively influence the chronic dialysed patient's prognosis in the absence of treatment $(12,13)$.

\section{PARAMETERS FOR THE EVALUATION OF CHRONIC HEMODIALYSIS EFFICIENCY}

\section{Urea reduction rate (URR)}

An important tool for the evaluation of dialysis adequacy is the urea reduction rate (URR). This is due to the fact that the percentage of the decrease of serum urea is the result of the treatment. The first hypothesis regarding the linear urea reduction was contradicted by later observations. It was thus found that during the first part of dialysis the urea reduction rate is higher than in the second part of the procedure. In other words, the serum urea decreases more steeply during the first part of the dialysis than towards the end. About 60 minutes post-dialysis, the serum urea values are much higher than the values found at the beginning of the dialysis. The phenomenon can be explained by the fact that during dialysis a percentage of the urea remains at tissue level (e.g. muscles); this amount of urea diffuses at blood level once the procedure is over. Delaying blood drawing to analyze the urea reduction rate is not recommended.

URR is calculated using the values of serum nitrogen pre- and postdialysis; the formula used is:

$\mathrm{URR}=1$-Urea post-dialysis/Urea pre-dialysis $\mathrm{x}$ 100.

It is to be noted that this evaluation instrument of dialysis adequacy depends primarily on the ability of the dialyzer to eliminate urea; the time of the hemodialysis session, the effect of ultrafiltration and the body surface area are not taken into account $(12,14)$.

A minimum of $65 \%$, with a target of $70 \%$, is the recommanded amount $(12,14)$.

\section{$\mathrm{Kt} / \mathrm{V}$ using urea reduction}

Another parametre to evaluate the adequacy of the dialysis, based on the urea reduction rate, the ultrafiltrated volume and the length of the session, is $\mathrm{Kt} / \mathrm{V}$. The mathematical formulas are:

$\mathrm{Kt} / \mathrm{V}=-\ln \mathrm{R}+(3 \times(\mathrm{UF} / \mathrm{W})) / 1-0.01786 \mathrm{t}$ and $\mathrm{Kt} / \mathrm{V}=(-\ln (\mathrm{R}-0.008 \times \mathrm{t}))+((4-3.5 \times \mathrm{R}) \times(\mathrm{UF} / \mathrm{W}))$

(12) (14) 


\section{The model of urea kinetics}

The model of urea kinetics refers to the changes which occur in the urea balance; the urea clearance through the dialyser and the kidneys, as well as the generation and distribution of urea in the subject are considered. In case of intermittent dialysis, within this model, besides the parameters above-mentioned, the changes in the body fluids and the urea intermittent clearance performed by the dialyzer are considered.

The model of urea kinetics represents the basis for obtaining $\mathrm{Kt} / \mathrm{V}$ - one of the parameters used to evaluate the hemodialysis efficiency, where Kt represents the volume of purged plasma, and V represents the volume of urea distribution. More specifically, $\mathrm{K}$ signifies the urea corrected clearance, obtained from the producer (periodically measured and checked), $t$ represents the length of the dialysis session, and $\mathrm{V}$ represents the total volume of water. spKt/V (single-pool Kt/V) and eKt/V (Kt/V balanced) are used in practice $(12,13,14,15)$.

\section{Single-pool Kt/V $(s p \mathrm{Kt} / V)$}

The urea kinetic modelling through $\mathrm{sp} \mathrm{Kt} / \mathrm{V}$ is based on the hypothesis that urea is found in only one compartment, which determines its linear decrease during the entire session. It should also be reminded that there is a rebound of the serum urea when urea leaves the area where it was kept (e.g. muscles). The major disadvantage of $s p K t / V$ is the overestimation of the level of serum urea and the quantity purged during dialysis.

The spKt/V target value is 1.4 corresponding to a $70 \%$ URR. At the same time, a spKt/V of $1.2 \mathrm{~min}-$ imum, corresponding to a $65 \% \mathrm{URR}$, is accepted for an adequacy treatment $(12,13,16)$.

\section{Balanced $\mathrm{Kt} / \mathrm{V}(\mathrm{eKt} / \mathrm{V})$}

The rate of transfer of urea from the tissue where it is kept is taken into account in urea kinetic modelling; this is why the blood samples used to evaluate the post-dialysis amount of urea can be obtained even after 30-60 minutes following the procedure. $\mathrm{Kt} / \mathrm{V}$ is a widely-used parametre because it offers accurate information, compared to spKt/V $(12,13$, 16).

Taking into consideration the fact that the urea clearance at kindney level is included in the urea kinetic modelling, in patients with residual kidney function (GFR $>2 \mathrm{ml} / \mathrm{min} / 1.73 \mathrm{~m}^{2}$ ) $\mathrm{Kt} / \mathrm{V}$ values lower than those for the patients with GFR under $2 \mathrm{ml} / \mathrm{min} / 1.73 \mathrm{~m}^{2}$ are accepted. At the same time, the studies in specialist literature describe a better evolution in patients with residual kidney function after the onset of chronic hemodialysis $(12,16)$.
Although the specialist literature has not yet defined the concept of "adequate dose" of hemodialysis, different targets have been evaluated. Certain guides recommend a minimal value of 1.2 balanced $\mathrm{Kt} / \mathrm{V}(\mathrm{eKt} / \mathrm{V})$ for the HD treatment 3 times a week, while others recommend a target of $1.4 \mathrm{Kt} / \mathrm{V}$ (spK$\mathrm{t} / \mathrm{V})$ single pool $(12,16)$.

Observational studies emphasize the fact that a larger dose of hemodialysis is associated to increased survival $(12,13,16)$.

$U K$ Renal Association and K/DOQI recommends a minimal 1.2.for $\mathrm{spKt} / \mathrm{V}$. This $\mathrm{spKt} / \mathrm{v}$ value represents approximately $15 \%$ of the value of the renal clearance and corresponds to $1.05 \mathrm{eKt} / \mathrm{V}$ and $65 \%$ URR $(12,15)$. The HEMO Study (the Hemodialysis Study) for an efficient dialysis suggests 1.25 standard spKt/V and a high value of 1.65 (high dose of dialysis). $1.65 \mathrm{spKt} / \mathrm{V}$ corresponds to 1.45 $\mathrm{eKt} / \mathrm{V}$ and $75 \%$ URR. It should be pointed out that the study did not find significant differences in mortality rates related to the 2 doses of hemodialysis (1.25 standard dose and 1.65 high dose) $(12,14,16)$.

The present recommendations in K/DOQI 2015 guides are (16):

- The recommended target dose of the dialysis $(\mathrm{spKt} / \mathrm{V})$ is 1.4 / hemodialysis session for patients treated 3 times a week with a minimum $1.2 \mathrm{spKt} / \mathrm{V}$.

- In patients with significant residual native kidney function the dose of hemodialysis can be decreased on condition, the renal function is periodically monitored in order to avoid inefficient dialysis.

- For a schedule other than 3 sessions/week, the standard $\mathrm{kt} / \mathrm{V}$ is 2.3 volumes per week, with a minimal delivered dose of 2.1 using a formula which includes ultrafiltration and residual kidney function.

According to National Cooperative Dialysis Study (NCDS), Kt/V $<0,8$ represents a marker for high mortality (17).

\section{ALTERNATIVE METHODS TO EVALUATE THE EFFICIENCY OF HEMODIALYSIS}

\section{The index of solvates removal}

This parametre involves calculating the total urea purged during the dialysis session using the urea concentration in dialysis and the dialysate volume used during the session. The special advantage of the method is that it is not influenced by the variations of serum urea. Nevertheless, the method 
presents certain disadvantages, such as: the difficulty to collect the used dialysate and the lack of studies on its use in evaluating the long-term evolution of chronic hemodialysis patients (12).

\section{The protein catabolic rate (PCR)}

The protein catabolic rate is frequently calculated in the model of urea kinetics. This parametre depends on the patient's weight, so $\mathrm{nPCR}=\mathrm{g}$ proteins $/ \mathrm{kgc} /$ day. It should be remembered that there is no inter-relationship between daily protein intake and urea generation. This is due to the fact that under certain situations, in spite of a reduced protein intake, nPCR is increased on account of intense muscle catabolism. Maintaining an optimal nutritional status of the chronically hemodialysis patient is important to reduce the patient's mortality and morbidity. The formula to calculate PCR is:

$\mathrm{PCR}=$ (pre-dialysis serum nitrogen - post-dialysis serum nitrogen) $\mathrm{X}(0.045 / \mathrm{T})$, where T represents the number of days between the times when the blood samples were drawn (pre-/post-dialysis).

The target for normal catabolic rate suggested in specialist literature is $1 \mathrm{~g} / \mathrm{kgc} /$ day.

A serum albumin level over $4 \mathrm{~g} / \mathrm{dl}$ and plasma cholesterol between $200-300 \mathrm{mg} / \mathrm{dl}$ are useful parametres in evaluating the adequacy of chronic hemodialysis $(12,13)$.

\section{Acidosis}

Pre-dialysis serum bicarbonate should have values ranging within normal limits $(20-24 \mathrm{mEq} / \mathrm{l})$ for a good management of the chronically dialysed patient. It is for this reason that the level of bicarbonate should be adjusted according to each patient's needs during the hemodialysis session. The transfer of the bicarbonate from the dialysate into the blood depends on the URR and Kt/V values (13).

\section{Ultrafiltration}

The change of the patient's volemia directly influences the $\mathrm{Kt} / \mathrm{V}$ value. This is due to the change of the overall volume of water in the body. As it follows, in edematous syndromes, with constant urea clearance $(\mathrm{K})$ values and keeping the same length of the hemodialysis session, with an increase of the overall volume of water, $\mathrm{Kt} / \mathrm{V}$ decreases (13).

\section{Malnutrition}

Maintaining an optimal nutritional status confirms the adequacy of chronic hemodialysis. It should be remembered that monitoring only the patient's dry weight, confusions may sometimes occur, since the loss of muscle mass can be hidden by liquid retention. To avoid this phenomenon, the specialist literature presents scores for monitoring the patient's nutritional status; this include parame- ters like average $\mathrm{Kt} / \mathrm{V}$ rate, $\mathrm{Hb}$ serum level, $\mathrm{PTH}$, $\mathrm{PO}_{4}$, albumin, standard mortality rate and the central venous catheters (13).

6. The product resulting from the length of the hemodialysis session and its frequency

This parameter for the evaluation of chronic hemodialysis highlights the importance of the frequency of the hemodialysis sessions, as well as their length. The formula is:

$\mathrm{HDP}=\mathrm{No}$. of hemodialysis $\mathrm{X}$ (no of sessions per week) $)^{2}$

Since a minimum of 72 is considered to be optimal for the efficiency of the dialysis session, a suitable treatment recommended to consist of 3 dialysis sessions per week, each lasting 4 hours (13).

\section{DISCUSSIONS}

Modern dialysis machines allow for the continuous online collection of some dialysis parametres in real time (18). Online monitoring showed there is a variation of the delivered dialysis dose $(\mathrm{kt} / \mathrm{V}$ urea) among treatments (19). Furthermore, a retrospective study on over 33.000 patients, reported a significant association between the variability of the delivered hemodialysis dose and mortality. The variation was measured in a certain patient who underwent dialysis three times a week (as annual frequency of dialysis), with $1.2 \mathrm{spKt} / \mathrm{V}$ and an annual average of $\geq 1.2 \mathrm{spKt} / \mathrm{V}$ (20).

The online clearance is available using standardized methodologies, which include calculating $\mathrm{kt} / \mathrm{V}$ urea. The present online methods quantify the clearance by analyzing the conductivity of the dialysate entering and leaving the dialyzer, as response to the electrolytic composition of the dialysate, or by refractometry (21). The online monitoring allows for early detection and correction of the dose variations between sessions. Certain possible errors in the technique of blood drawing ca be identified and avoided, as well. As a result, the objective and unbiased reporting of the dialysis dose can be provided and every treatment can be quantified. Furthermore, online monitoring can assist in the early detection of possible complications of vascular access, a fact which allows the medical staff to take measures in due course $(22,23)$.

The online monitoring of treatment variables, such as: diffusion time, the real blood flow, the frequency of alarms, arterial pressure, venuos pressure, the entire volume of dialysed blood, the ultrafiltration rate, intradyalitic hypotension and the sodium balance can also be used for a better analy- 
sis of the quality of the treatment in a particular patient, which allows for safe individualized therapy.

\section{CONCLUSIONS}

The constant evaluation of the hemodialysis adequacy and the adjustment of treatment according to individual needs are important factors in achieving a suitable management of the chronically hemodialysis patients and in improving their longtime prognosis.

\section{Acknowledgement}

All authors have contributed equally to the present work and thus are main authors.

\section{REFERENCES}

1. Liyanage $T$, Ninomiya $T$, Jha $V$ et al. Worldwide access to treatment for end-stage kidney disease: a systematic review. Lancet 2015; 385: 1975-82.

2. Tănăsescu MD, Balcangiu Stroescu AE, Răducu L, Limbau AM, Diaconescu AC, Bălan DG, lonescu D. Uterine cervical cancer and chronic kidney disease an association that should not be skipped. Rev. Chim. (Bucharest), 69, No.9, 2018, pp.2524-2526.

3. Anders HJ, Vielhauer V. Renal co-morbidity in patients with rheumatic diseases. Arthritis Res Ther. 2011; 13(3): 222.

4. Tonelli M, Wiebe N, Culleton B, House A, Rabbat C, Fok M, McAlister F, Amit X. Chronic Kidney Disease and Mortality Risk: A Systematic Review. JASN July 2006, 17 (7) 2034-2047.

5. Balcangiu-Stroescu $A E$, Tănăsescu MD, Diaconescu $A C$, Răducu $L$, Constantin AM, Bălan DG, Ţărmure V, lonescu D. Cardiovascular comorbidities, inflammation and serum albumin levels in a group of hemodialysis patients. Rev. Chim. (Bucharest), 69, No. 4 , 2018, pp.926-929.

6. Balcangiu-Stroescu AE, Tănăsescu MD, Diaconescu AC, Răducu L, Daniela Gabriela Bălan DG, lonescu D. A brief presentation of the characteristics of hemodialysis membranes. Materiale Plastice, 55, No. 3, 2018, p:332-334.

7. Totan A, Balcangiu-Stroescu AE, Melescanu Imre M, Miricescu D, Bălan D, Stanescu II, Ionescu D, Timofte D, Tănăsescu MD, Greabu $\mathrm{M}, \mathrm{XOR}$. Possible Correlations with Oxidative Stress and Inflammation Markers in the Context of Diabetic Kidney Disease. Rev. Chim. (Bucharest), 70, No.4, 2019, pp.1396-1398.

8. Balcangiu-Stroescu AE, Tănăsescu MD, Diaconescu AC, Răducu L, Bălan DG, Mihai A, Tănase M, Stănescu II, lonescu D. Diabetic nephropathy: A concise assessment of the causes, risk factors and implications in diabetic patients. Revista de Chimie. (Bucharest), 69, No.11, 2018, pp.3118-3121.

9. Bălan DG, Balcangiu-Stroescu AE, Tănăsescu MD, Diaconescu AC, Răducu L, Mihai A, Tănase M, Stănescu II, Ionescu D. Nutritional intervention in patients with diabetic renal disease - a brief presentation. Revista de Chimie.(Bucharest), 69, No.11, 2018, pp.3178-3182

10.https://www.exerciseismedicine.org/assets/page_documents/ PHM\%20Roadmap\%20HL.pdf accesat mai 2019.

11. Canaud B, Hegbrant J, Nissenson AR, Barth C, Maddux F, Etter M, Krishnan M. Improving outcomes of dialysis patients by population health management - the Global Chief Medical Officer Initiative. The Lancet, Vol 388, Issue 10055, pp. 1966-1967.
12. Siriopol D, Voroneanu L, Covic A. Physiologic principles of hemodialysis. In: Adrian Covic, Hemodialysis: theoretical and practical principiles, Demiurg Printing House, 2010, pp.47-59.

13. Levy J, Morgan J, Brown E. Oxford Handbook of Dialysis, 4th Edition, Oxford University Press, 2016, pp.162-170.

14. Suhaid A. Chapter 6 Dose of Hemodialysis. In: Suhaid Ahmad, Manual of Clinical Dialysis, Second Edition, Springer Science+Business Media, LLC 2009, pg:79-93.

15. Gotch FA. Urea kinetic modeling for guiding hemodialysis therapy in adults. In: Allen R Nissenson, Richard N. Fine, Handbook of Dialysis Therapy, 5th Edition, Elsevier, 2017, pp.264- 273.

16. National Kidney Foundation. KDOQI clinical practice guideline for hemodialysis adequacy: 2015 update. Am J Kidney Dis. 2015; 66(5):884-930.

17. Gotch FA, Sargent JA. A mechanistic analysis of the National Cooperative Dialysis Study (NCDS). Kidney Int. 1985 Sep; 28(3):52634.

18. Alquist M, Bosch JP, Barth C, Combe C, Daugirdas JT, Hegbrant JBA, Martin G, McIntyre CW, O'Donoghue DJ, Rodriguez HJ, Santoro A, Tattersall JE, Vantard G, Van Wyck DB, Canaud B. Knowing What We Do and Doing What We Should: Quality Assurance in Hemodialysis. Nephron Clinical Practice 126(3):135-143.

19. McIntyre CW, Lambie SH, Taal MW, Fluck, RJ. Assessment of hemodialysis adequacy by ionic dialysance: intra-patient variability of delivered treatment. Nephrol Dial Transplant 2003; 18: 559-563.

20. Walters B, Pennell P, Hegbrant JBA, Nabut J, Bosch JP. The frequency of exposure to a dialysis dose of less than single-pool (sp) $\mathrm{Kt} / \mathrm{V}$ of 1.2 predicts decreased survival in hemodialysis patients. Nephrol Dial Transplant 2003;18(suppl 4):170.

21. Daugirdas JT, Tattersall JE. Automated monitoring of hemodialysis adequacy by dialysis machines: Potential benefits to patients and cost savings. Kidney Int 2010; 78: 833-835.

22. Mohan S, Madhrira M, Mujtaba M, Agarwala R, Pogue V, Cheng JT. Effective ionic dialysance/blood flow rate ratio: An indicator of access recirculation in arteriovenous fistulae. ASAIO J 2010; 56; 427-433.

23. Tan J, Mohan S, Herbert L, Anderson H, Cheng JT. Identifying hemodialysis catheter recirculation using effective ionic dialysance. ASAIO J 2012; 58: 522-525. 